\title{
Virtual prototyping for open building design
}

Article in Open House International · December 2011

CITATIONS

4

2 authors, including:

\section{Şule Taşlı Pektaş}

Bilkent University

26 PUBLICATIONS 145 CITATIONS

SEE PROFILE
READS

7 


\title{
VIRTUAL PROTOTYPING FOR OPEN BUILDING DESIGN
}

\section{Şule Taşıı Pektaş \& Bülent Özgüç}

\begin{abstract}
This paper re-visits the basic premises of open building: designing for change as well as for stability, including the users in the design decision-making processes, and disentangling the building systems into the levels and allowing replacement; then, addresses the limitations of conventional design media in terms of the capabilities to support these aims. It is discussed that the design media should be predictive, dynamic, and interactive. Virtual prototyping as an enabling technology is reviewed and proposals are made for the future use of this technology for open building design.
\end{abstract}

Keywords: Open Building Design; Design Media; Computer-Aided Design; Virtual Prototyping; Performative Design

\section{INTRODUCTION}

Open building is an innovative way of producing user-oriented environments. It aims to ensure that design decisions will enable buildings and urban fabric to remain valuable well into the future, because they are planned for change as well as stability. The origin of the open building approach is based on the ideas of Habraken (1962) who proposed building support structures as an alternative to mass housing in 1960s. In 1965, SAR (Foundation for Architects' Research) was founded in Netherlands for encouraging industrialization in housing and this organization played a central role in the development of open building. The approach attracted attention in Japan, Finland, the United Kingdom, and then all around the world, as documented by "Open House International" which served as the primary resource for the theory and practice of open building since 1976. The International Council for Research and Innovation in Building and Construction (CIB) has been including a working commission entitled "CIB W104 Open Building Implementation" which is an international network of researchers and practitioners who subscribe to the open building approach (CIB W104 2010). Currently, open building movement is developing further through publications, scientific meetings, and practical work.

Open building can be conceptualized as a number of distinct but related ideas about design- ing environments (Habraken 2010). First of all, the approach is based on the premise that buildings are not static artefacts, but they are in constant transformation and change. Thus, open building differs from the conventional way of building in which a single program is adapted; since it recognizes that a single program would not be enough to satisfy a wide range of needs and preferences as well as the future demands of the occupants. Another aspect of change that should be addressed within the framework of open building is the dynamic environmental factors such as thermal, acoustical, and lighting conditions and the performance of buildings in response to these elements. Sustainability in the built environment is a primary goal of open building and it is widely accepted that sustainability can only be realized with well-rooted insights into the interactions between buildings and their environments.

The open building approach also acknowledges that building design is a collaborative process, which involves many participants with diverse backgrounds. Thus, the management of the decision-making processes in building design is of utmost importance to reduce complexities and to balance divergent interests of the related parties. Involving the users in the decision-making process is a priority in open building since it is recognized that mass housing had excluded such participation almost entirely from the process.

Another main principle of open building is 


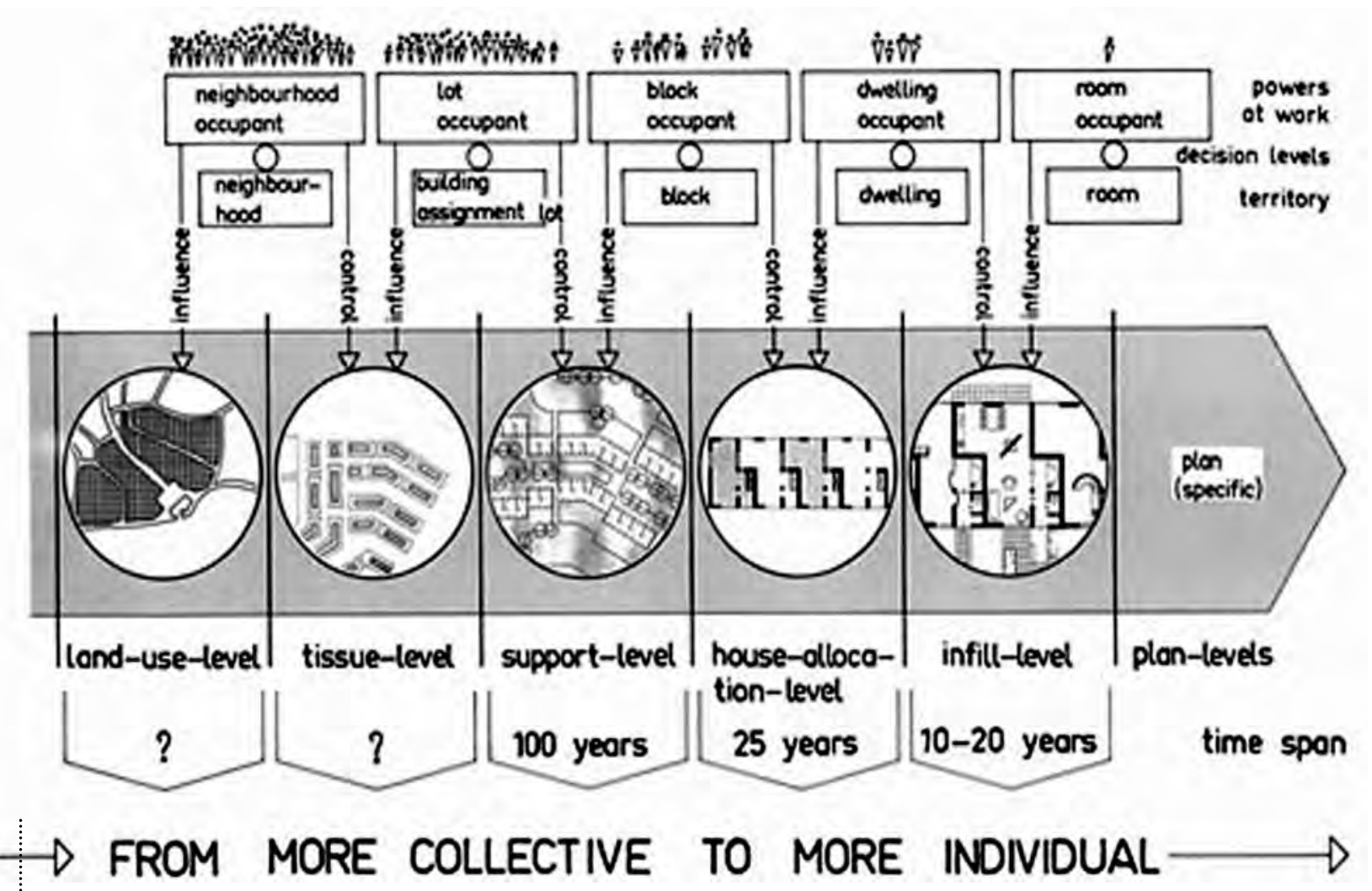

\section{Figure 1. Levels in open building design (Agile Architecture Web Site 2011)}

designing and building with environmental levels (Figure 1). These levels naturally correspond to design professionals who operate according to certain levels of intervention: urban designers, architects, and interior designers work at distinct "resolutions" of built environment. The idea of levels is a familiar one, but the unique contribution of the open building approach to this idea is the formal recognition of these levels such as city structure, support, and infill levels and the recommendation for the disentanglement of them. The disentanglement enables replacement or repair in a level without disturbing another. For example, alterations can be made in infill without disturbing support level, whereas in conventional building, the whole building must often be altered in this case.

Although open building was studied and practiced with many different perspectives within the framework explained above, the studies on the relations between design media and open building are rare. This is surprising because it is also known that open building proponents often suggested the use of advanced visualization technology. The importance of the use of information technology in both design and manufacturing processes of open building was mentioned by Kendall and Teicher (2000), Gann (1999), Tiuri and Hedman (1998), Zaman and Ganesan (1996), besides many others. However, a systematic analysis of design media in relation to the aims and principles of open building is still lacking in the literature. In order to alleviate the problem, this study aims to analyze conventional design media in terms of capabilities to support open building design and to propose solutions to overcome the limitations of the existing media by the help of the latest developments in information technology. The paper is organized in four sections. First, a critical review of conventional design media is presented. Then, virtual prototyping in engineering design is discussed as an innovative approach towards dynamically simulated computer graphics. In the light of the recent developments, some proposals for the use of virtual prototyping for open building design are presented in the third section. Finally, some challenges of virtual prototyping for open building purposes are addressed and suggestions are made for further research. 


\section{A CRITICAL REVIEW OF CONVENTIONAL DESIGN MEDIA}

In architectural design, modelling is a process, either mental or externalized, of translating conceptual ideas into visual forms. Although at its root the idea of modelling has been the same throughout the history, it has taken on many forms of expression. These expressions are mainly the result of technological advances in producing imagery. Design media can be analyzed under two headings; namely, traditional media (such as drawings, scale models, full scale mock-ups) and digital media (such as drafting-oriented software, threedimensional modelling software, and Building Information Modelling (BIM) tools). Traditional media changed only a little throughout the history, however, the transformation of the digital media was tremendous. Although computer graphics and Computer-Aided Design (CAD) revolutionized modelling media in architectural design, digital media was often used by architects as a replica of paper. Consequently, CAD was embraced by building designers merely for saving time in design production and gained acceptance as a term referring to automated drafting with the " $\mathrm{D}$ " in "CAD" actually read as "drafting." This was probably due to the misconception of the earlier CAD systems as simple devices for manipulating graphics just like word processors for manipulating texts. Even in academia this opinion seems to be still prevalent among those who is reluctant to integrate digital design applications with their practices (Pektas and Erkip 2006).

Three-dimensional modelling and visualization in motion introduced a new dimension to architectural representation in 1990s. The demands of clients were the main driving force for the widespread use of such tools. The public was exposed to high-end graphics on a regular basis in games, on TV and in movies. It was this type of output that most of the clients began to demand during that period (Mahoney 1997). Besides these presentation-oriented developments, there were also efforts to reinterpret the computer as a tool for processing and communicating information about buildings. Building information modelling tools (such as Autodesk Revit ${ }^{\circledR}$, VectorWorks Architect ${ }^{\circledR}$, and Bentley Architect $\AA^{\prime}$ ) were developed to integrate design information with the geometry, however, studies indicated that such tools were primarily used by architects as visualization tools ignoring their other functionalities (Gonchar 2006).

The main criticism of conventional design media (either traditional or digital) proposed in this paper, focuses on the limitations of the media in representing the wide contexts of built environments as recognized by the open building approach. Although drawings and three-dimensional models have been the major interpretation of designs throughout the history, they are rather abstract representations that are not related directly to the context of use. Of course, this abstractness serves for "representational economy" and saves time in the process. However, when the increasing complexity of design processes and the costs of design mistakes are concerned, the need for expanding the limits of the conventional representation tools becomes clear.

The open building approach defines the built environment as a huge and dynamic system consisting of many intermingling sub-systems. Through the conventional design media, knowledge about these systems is represented primarily through a normative process. Such knowledge is based on designers' own experience of what has worked in the past, or that of some peers' embodied in existing buildings that can be observed. If the normative approach is used exclusively, it is very limited due to the general nature of this knowledge. Since any departure from a solution that has worked before leaves the designer with no point of reference, original solutions are discouraged and the basic designs tend to remain unchanged. Remaining designs unchanged, the less obvious mistakes can become "fossilized" and carried from one building to the next. Moreover, rules of thumb are often incomplete, partial or contradictory. Since they are developed from past experience (because there is no theoretical guide) a failure of a rule cannot lead to any advance in providing better rules. AlKodmany (2001) also mentioned that used on their own, the conventional uses of design media lack the capabilities for sophisticated analysis and visu-

\footnotetext{
1 Revit is a trademark of Autodesk; VectorWorks Architect is a trademark of Nemetschek; Bentley Architecture is a trademark of Bentley. 
alization which render such representation less helpful for informed design decisions.

Mitchell (1993) contrasts the rigidity and limitations of "design-by-drawing" with the responsiveness of the craft process. He explains that trial and error is separated from production by using a scale drawing instead of the product as the medium of experiment and change. The scope for using drawings and physical scale models as a means of producing well-adapted designs is limited, because, "The principle of deciding the form of the whole before the details have been explored outside the mind of the chief designer does not work in novel situations for which the necessary experience cannot be contained within the mind of one person." Thus, in design-by-drawing, designers tend to focus on visual articulation and ignore non-visual aspects of design that the scale drawing fails to represent (Mitchell 1993). Having recognized the importance of trial and error through the media, Zaman and Ganesan (1996) suggested the use of full-scale "mock-up" models for open-building projects. However, the use of a real prototype is mostly not feasible in building design due to the high costs and one-of-a-kind nature of building designs i.e. uniqueness of every building.

Within this perspective, the present paper suggests that the proper media for open building design should be:

- Complex rather than simple,

- Predictive rather than merely descriptive,

- Dynamic rather than static, and

- Interactive rather than one-way.

The next chapter discusses an emerging type of media in engineering design, which seems to be developing towards this direction.

\section{AN APPROACH TOWARDS DYNAMICALLY SIMULATED COMPUTER GRAPHICS: VIRTUAL PROTOTYPING}

Engineering design is pioneering in innovative uses of design media. In the second half of the 1990s, virtual prototyping emerged in engineering design as an alternative to the conventional means. Although there are various definitions of the term in the literature, a virtual prototype generally refers to a dynamic, interactive, often immersive threedimensional CAD model developed to analyze designs. It is "intelligent" enough to capture product content, generate and simulate manufacturing processes, and predict product behaviour. In other words, virtual prototyping software not only simulates the way things look but also the way things work. They enable designers to check for potential design problems, such as difficulty in accessing components and completing assembly sequences. Designers can perform several "what-if" tests prior to the development of the first real prototype.

A compact definition of the term is the following: "A virtual prototype is a computer simulation of a physical product that can be presented, analyzed, and tested from concerned product lifecycle aspects such as design/engineering, manufacturing, service, and recycling as if on a real physical model. The construction and testing of a virtual prototype is called virtual prototyping..."Digital prototype" or "digital mock-up" are the terms used interchangeably with the term "virtual prototype" in the literature" (Wang 2002). Once built, a virtual prototype can be used in the whole product life cycle from preliminary design to cost estimation, manufacturing, and marketing. The use of virtual prototyping optimizes the design performance, increases collaboration, reduces costs and shortens time to production (Jimeno and Puerta 2007; Cecil and Kanchanapiboon 2007).

An interesting application area of virtual prototyping is "virtual manufacturing" or "virtual assembly." The term "virtual manufacturing" involves the use of virtual prototyping techniques to aid in manufacturing design issues. "Virtual assembly" can be used to describe the use of virtual prototyping for assembly-oriented analysis. Such simulation facilitates for comparing and modifying the process alternatives and checking for the manufacturability of the products (Cecil and Kanchanapiboon 2007) (Figure 2).

Virtual prototypes are often accompanied with virtual human models to study human-product interaction. Ergonomic virtual humans can be produced with varying degrees of complexity from simple human structure representation models to complex reactions and decision-making models (Honglun, Shouqian, and Yunhe 2007). Such sim- 


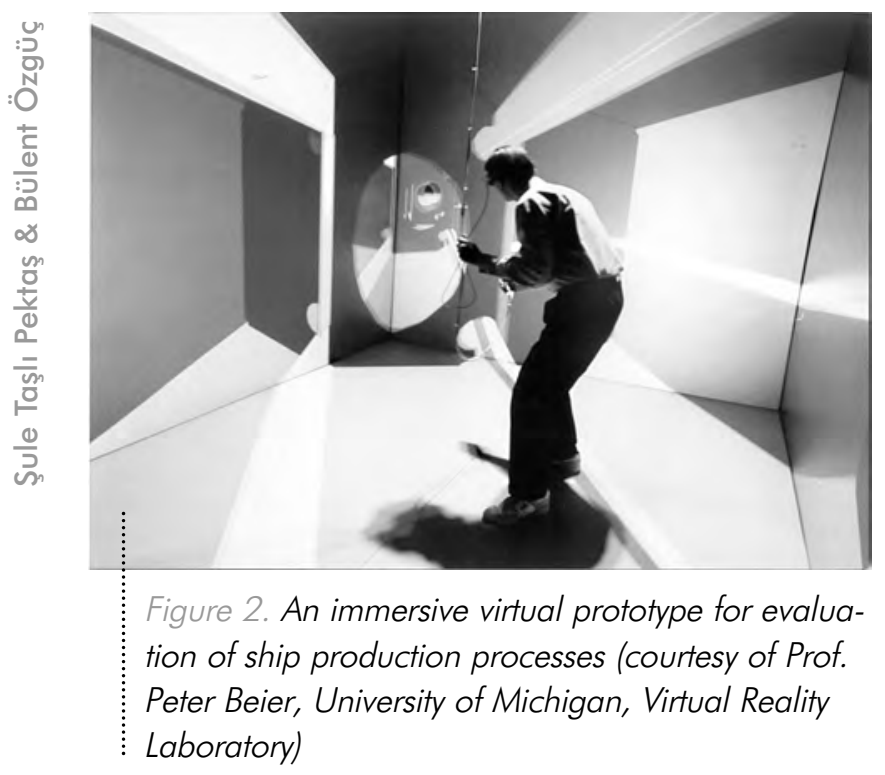

ulations provide insight into a product's usability, and help to determine the optimal sizes and placement of components based on the information. Virtual humans can also be added to the virtual manufacturing environments. Humans are also modeled in terms of their interactions with artefacts considering issues such as arm's reach, posture and decision-making when performing activities.

The availability of massive computer power, huge system bandwidth, and industry leading graphics -all with the decreasing costs- led to the acceptance of virtual prototyping as a viable design tool. In the current state of the technology, there is still a long way to go to compose (for example) an entire commercial airplane as a virtual prototype, however, several major industries, such as aerospace, automotive and shipbuilding, are already using this technology for design testing applications. Virtual prototyping was used successfully for mechatronic system design (Shen and Grafe 2007), robot design (Sang et al. 2010), automotive design (Erdelyi and Talaba 2010), aircraft design (Zhu, Larosa, and Ma 2009), and digital handheld product design (Park, Moon, and Lee 2009) to name a few (Figure 3).

\section{PROPOSALS FOR THE USE OF VIRTUAL PROTOTYPING FOR OPEN BUILDING DESIGN}

A single three-dimensional digital model that includes the behaviour of design elements has long $-50$

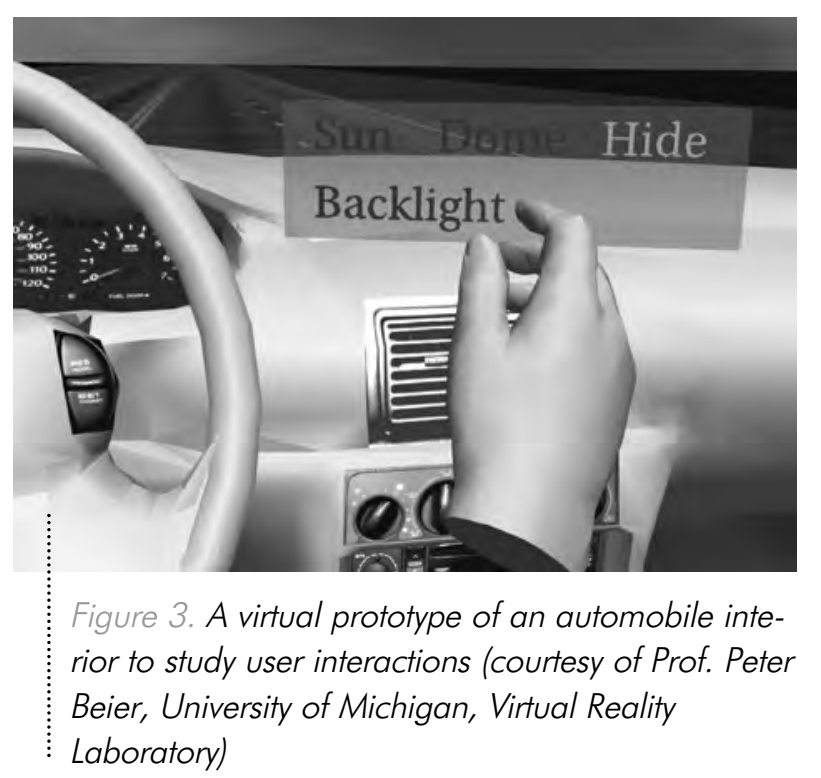

been a dream for CAD researchers, however the technology matured enough only in the last two decades to enable such applications. Taking clues from the developments in engineering design, we claim that virtual prototypes of buildings will be the next important step in digitalization of building representations. Decreasing costs and improving functionality of computer technology are transforming digital design media towards this aim. In the light of the recent developments, some proposals for the use of virtual prototyping for open building are presented below.

\section{Designing for change}

"Designing for change as well as for stability" is an essential component of open building. Although buildings have static structures, everything else related to architecture is dynamic. Occupants, functions, and environmental conditions of buildings dynamically change throughout building life cycles. The types of such changes as recognized by open building literature include spatial changes, increasing or decreasing floor areas, changing functions (Habraken et al. 1976), user type, psychological and sociological issues related to users (Brezar 1996), and changing needs of different age groups like elderly (Tiuri and Hedman 1998). Thus, simulation as a means of imitating a real system and predicting its behaviour is an essential phase of an open building design process. Computers have had the ability of simulating most of the aspects of design for a long time, but such applications are not widely used in practice. This is mostly due to the 

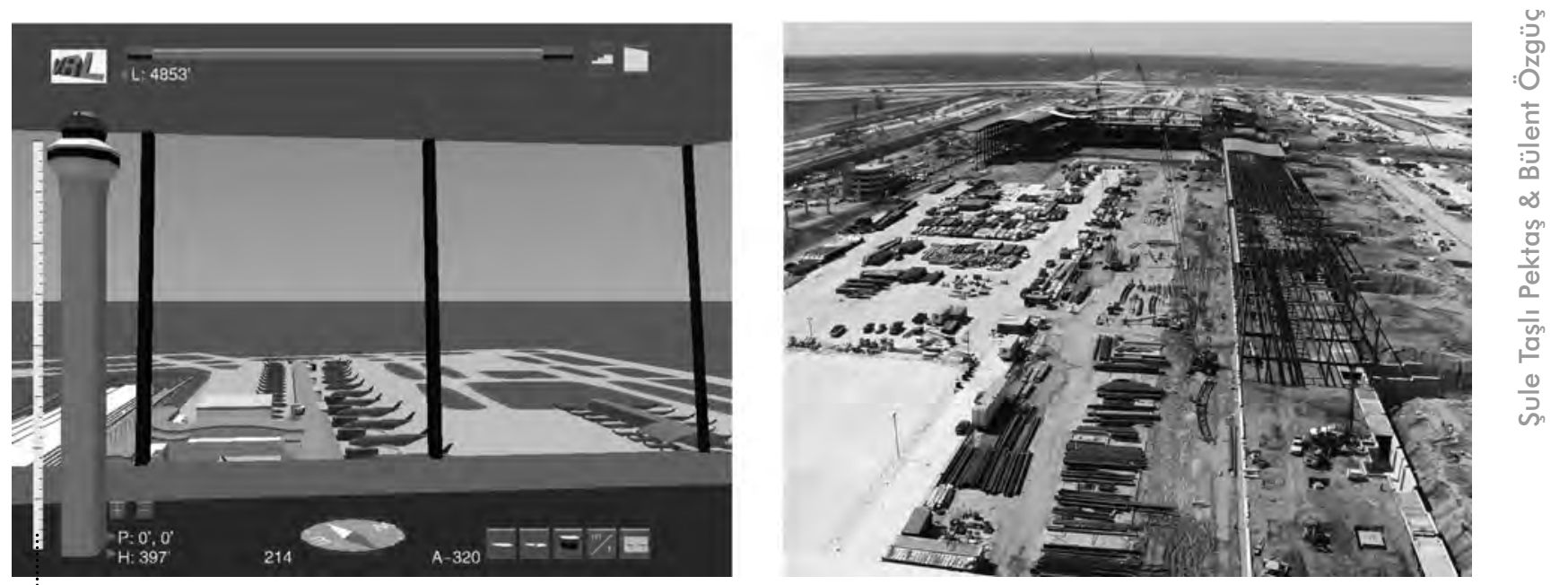

Figure 4. The use of virtual prototyping for design evaluation in Detroit Midfield Airport and Terminal Building: virtual model with controls to investigate the effects of change in design parameters (left) and a view from the actual construction site (courtesy of Prof. Peter Beier, University of Michigan, Virtual Reality Laboratory).

lack of integration between analysis and design tools. Conventional simulation tools leave building designers with a large amount of data, often in a format difficult to understand, so the practitioners are not very willing to use conventional performance simulation tools because of the non-graphical output and uncomfortable interface of such tools.

The discrepancy between form-generation and performance-evaluation in conventional design media has been increasingly recognized in recent years within the framework of "performative," or "performance-based" design approach (Oxman 2009; Kolarevic and Malkawi 2005). This approach addresses that in conventional building design practices, form generation is followed by performance evaluation. In this "generate and test" model, form generation takes priority over performance evaluation. It is argued that performance should be considered to be a shaping force rather than evaluative criteria. Oxman claims that the current international effort in building and engineering design is attempting to achieve a higher level of integration between form generation and evaluation which is now becoming realizable through transformation of design media by the help of methods such as parametric design, associative geometry, and generative processes (Oxman 2009).

Despite the gradual transformation of design media, experiencing design behaviour in an inte- grated way is yet only possible with the virtual prototyping approach. Virtual prototyping allows us to look at a system as a whole; a building is a perfect example for such a system. Virtual prototypes enable several "what-if" scenarios to analyze the results of change (Figure 4). Similarly, buildings' thermal, structural, acoustical and lighting behaviours can be analyzed by dynamically simulated virtual models. Such simulation often makes use of computational fluid dynamics that solves the equations governing fluid flow and translates the numeric solutions into easy-to-read dynamic graphics. Computational fluid dynamics can be used in architectural design to predict airflow, heat transfer, progress of a potential fire, and concentration of smoke. Auralization of sound in virtual environments i.e. rendering spatialized sound based on acoustic modelling, is another area of performance visualization. Such systems can compute reverberation paths from a sound source to a listener and visualize the results. Design behavior such as thermal insulation and acoustic isolation can be represented as colors, sounds, motion-models and other user-friendly representations and these can be directly mapped on the virtual model.

\section{User-oriented design}

Involvement of users in design decision-making processes is another principle of open building. The importance of advanced presentation techniques for user involvement in design and the limitations of 


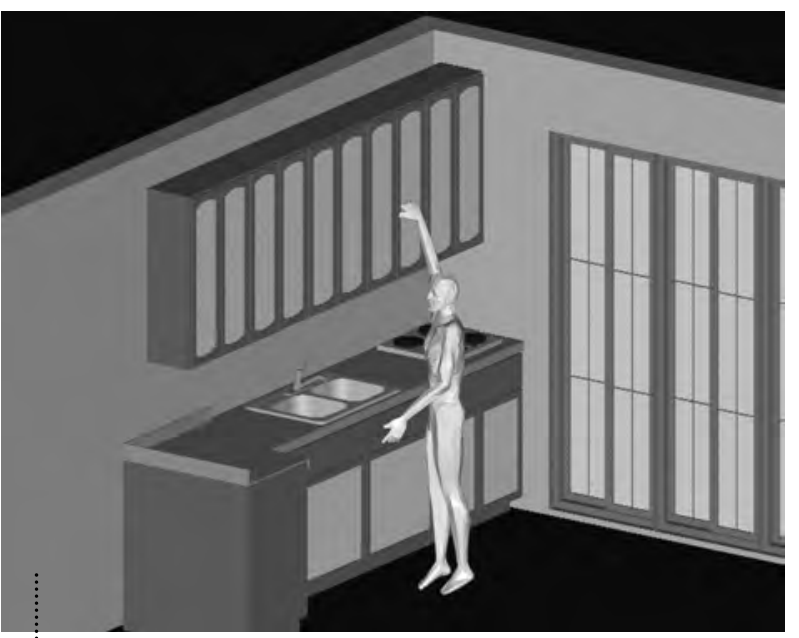

Figure 5. Ergonomic simulation of a virtual human testing kitchen cupboard design (Tasli and Sagun 2001)

conventional media in this respect were acknowledged in the open building literature (Kendall and Teicher 2000; Gann 1999; Tiuri and Hedman 1998). Habraken et al. (1976) defined the role of the designer in building design process as producing necessary design documents that can be understood by everybody easily. Similarly, Sanoff (1992) discussed that the participation of the users during the all phases of design would be possible if a design task could be made "transparent." Studies on virtual prototyping indicated that highly visual and interactive character of this type of modelling facilitates for the understanding and appraisal of designs by all the parties participating in design processes (Jimeno and Puerta 2007; Cecil and Kanchanapiboon 2007).

Another aspect of user-oriented design is considering human factors in design. However, the information needed for user responsive design is fragmentary, imprecise and highly subjective. Even if reliable information exists, it is not easily applicable for design purposes. Fortunately, human modelling software has already reached a level of maturity to be used in design testing applications. By combining the virtual model of the design with virtual humans, an architect can understand the possible results of interaction (Figure 5). Experiential user needs (like aesthetics, comfort and preferences) as well as accessibility and safety considerations can be analyzed. At the most advanced level, architects can become immersed in designs, "becoming" the user. For example, an architect designing a house for an elderly can benefit from
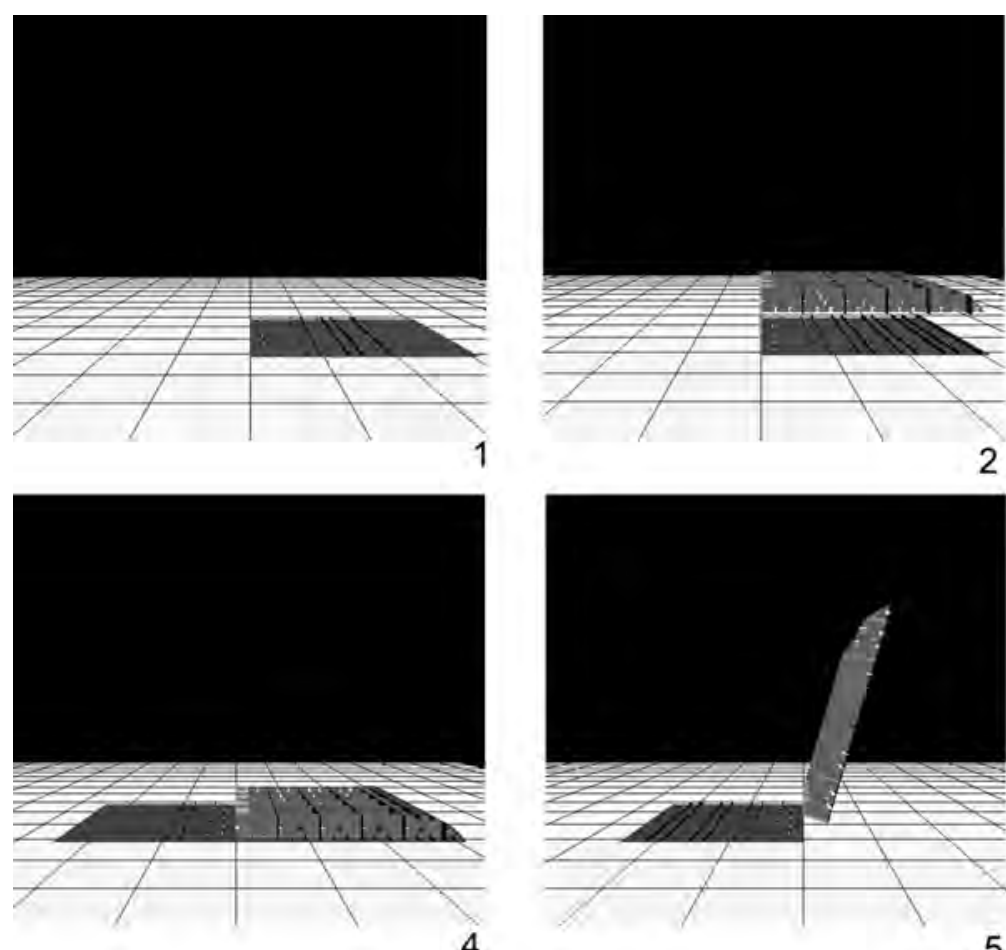

5

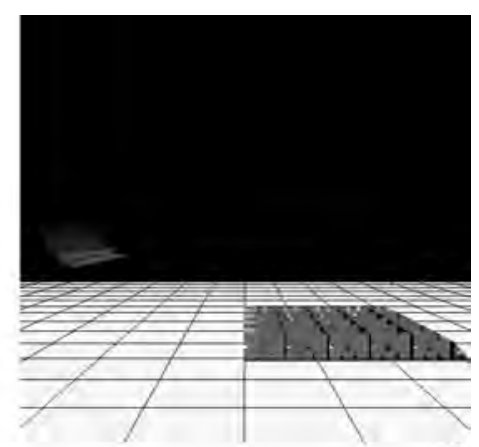

3

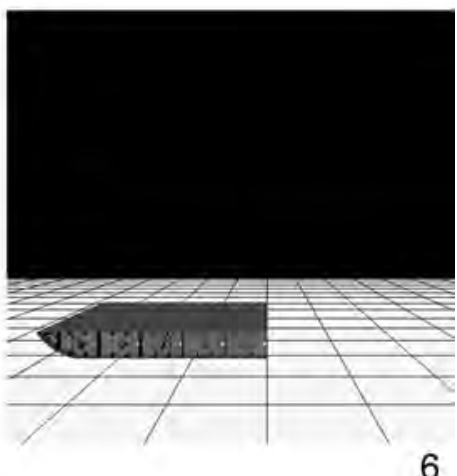

Figure 6. Screenshots from the dynamic virtual simulation of ship double bottom production process (courtesy of Prof. Peter Beier, University of Michigan, Virtual Reality Laboratory). 
"looking through the eyes" and "walking in the shoes" of that person. Moreover, simulations of groups help to analyze the events like evacuation, panic, or wayfinding in buildings.

\section{Open building process design}

Open building design also recommends disentangling the building systems and design decision making into the levels and allowing replacement in a level without disturbing the others. Clearly, such an aim necessitates planning the design and manufacturing processes. The relationship between open building and building design process management was addressed by Cuperus (2001) who claimed that open building can provide the basis for a well-structured design process. Limitations of the conventional tools in construction process management and benefits of virtual prototyping methods in this respect were documented in the literature (Guo, Li, and Skitmore 2010; Li et al. 2009). In fact, simulation of construction scheduling is the most widely known application of virtual prototyping in the construction industry. This type of simulation makes it possible to analyze construction processes and to optimize them. In a simulated construction environment, bottlenecks can be eliminated by trying out several "what if" scenarios. Constructability issues can also be analyzed (Figure 6).

\section{CONCLUSION}

To the best of the authors' knowledge this study is the first to analyze conventional design media in terms of capabilities to support open building design and to propose solutions to overcome the limitations of the existing media in reference to the latest developments in information technology. It is suggested that the use of virtual prototyping in open building can facilitate for designing user-oriented and change-responsive environments as well as for managing design and manufacturing processes. Although the benefits of virtual prototyping for open building purposes are noticeable, the challenges for future developments should also be addressed. The most important issues in this respect are listed below.

\section{Characteristics of the construction industry}

Up till now, virtual prototyping has been predominantly applied in industries such as automobile, aerospace, and consumer product industries; while its applications in the construction industry remained limited. This is probably due to some characteristics of the construction industry, which hindered such applications. First of all, unlike manufacturing industries, construction industry is fragmented into many small firms, which often have limited resources for advanced information technology applications. In fact, building up fully detailed 3D virtual prototypes still needs a lot of resources such as time and labour, but the developments in computer technology is continuously making detailed models more feasible and efficient. In the current state of development, we suggest that virtual prototypes of buildings can be designed to focus on the issues related to the purpose of model deployment. They can be partial but robust enough for systematic analysis.

Another challenge of the construction industry for virtual prototyping is the need for data collection. Any type of computer simulation necessitates that a great amount of information be collected. It is often acknowledged that construction industry lags behind the other industries in keeping the records of product and process information (Pektas and Pultar 2006). The lack of documentation in the industry seems to be a main challenge for building knowledge-intensive virtual prototypes. We suggest that the information needed for the production of dynamic simulations of buildings can be obtained from environmental design research. Design researchers often complain that their efforts are not respected enough by the industry. Besides the ignorance of the practitioners, this situation is also due to the inconvenient format of the outputs of such research for their competitive and pressuring market conditions. Virtual building prototypes can effectively make use of research data and present the results in an easy-to-follow way.

\section{Integration of design, analysis, and simulation tools} In building design, designers usually have to use two or more software packages to produce a highlevel model and the lack of compatibility between different programs often creates problems. Virtual prototyping is not an exception for this situation. 
Currently, most of the virtual prototyping systems require geometrical models to be created in a different CAD system. The data transfer between the systems is often one-way i.e. changes of the model in the virtual prototyping system cannot directly exported back to the initial CAD system. Some researchers offered specific tools which are able to transfer data among the different CAD and virtual prototyping software as a solution (Barbieri et al. 2008), but it seems that the problem persists. Thus, we recommend that further studies on virtual prototyping should rigorously address the integration issues.

\section{Interface design}

Interface design is another important issue that needs to be considered. CAD systems are often criticized on account of incompetent interfaces that shift attention from the design task to the interaction task. This obviously consumes time and energy. A design system should be quick and intuitive, capturing the flow of concepts as quickly and naturally as possible. Moreover, a virtual prototype designed for building professionals should enable them to get the information needed on their specific problems, make sense of it and reach decisions easily. Since building is a process including a number of professionals with different backgrounds (architects, engineers, facility managers, financiers, etc.) a common ground should be provided for different applications. Hence, interface designs enabling effective collaborations have to be studied as well.

\section{Validation of the models}

Validation of simulation models and representations for visualization is an important consideration. Validation of the model is required for any type of simulation to ensure that the mathematical model successfully represents the reality. There are several difficulties in modelling time, colours, and textures for virtual building prototypes. Since it is yet impossible to simulate the real visual experience, at the current state it would be proper to catch a likeness level that reveals the key aspects of a design rather than trying to simulate the whole experience. Moreover, visualization techniques and representations should well respond to the needs of the industry. Ease of use and avoidance of misinterpretations are the key concepts. There is a lack of standards for computer visualizations in general; hence, the related parties have to develop their own conventions according to their purposes.

This study provided insights into the limitations of conventional design media for open building purposes and suggested an innovative use of design media. Within the scope of the paper, the authors attempted to discuss many aspects of the subject. It is hoped that this paper would facilitate for further studies in this track.

\section{REFERENCES}

AGILE ARCHITECTURE WEB SITE, 2011, Available at:

http://www.agilearchitecture.com

Al-KODMANY, K. 2001, Visualization Tools and Methods for Participatory Planning and Design, Journal of Urban Technology, 8(2), pp. 1-37.

BARBIERI, L., BRUNO, F., CARUSO, F., and MUZZUPAPPA, M. 2008, Innovative Integration Techniques between Virtual Reality Systems and Cax Tools, International Journal of Advanced Manufacturing Technologies, 38, pp. 1085-1097.

BREZAR, V. 1996, Housing Design to Meet Future Upgrading, in O. Ural, D. Altınbilek and T. Birgönül, (Eds.) XXIVth IAHS World Housing Congress: How to House a Nation: The Challenge for the XXlst Century. Vol. 2, Ankara, Turkey, pp. 551-57.

CECIL, J., and KANCHANAPIBOON, A. 2007, Virtual Engineering Approaches in Product and Process Design, International Journal of Advanced Manufacturing Technologies, 31, pp. 846-856.

CIB W104, 2010, Open Building Implementation Web Site, available at: http://www.open-building.org/

CUPERUS, Y. 2001, An Introduction to Open Building, The $9^{\text {th }}$ International Group for Lean Construction Conference, Singapore, available at:

http://cic.vtt.fi/lean/singapore/CuperusFinal.pdf

ERDELYI, H. and TALABA, D. 2010, Virtual Prototyping of a Car Turn-signal Switch Using Haptic Feedback, Engineering with Computers, 26(2), pp. 99-110. 
GANN, D. 1999, Flexibility and Choice in Housing, The Policy Press, Bristol, UK.

GONCHAR, J. 2006, To Architects, Building Information Modeling is Still Primarily a Visualization Tool, Architectural Record, 194(7), p. 158.

GUO, H. L., LI, H., and SKITMORE, M. 2010, Life Cycle Management of Construction Projects Based on Virtual Prototyping Technology, Journal of Management in Engineering, 26(1), pp. 41-47.

HABRAKEN, J. 1962, De Dragers en de Mensen, Amsterdam: Scheltema en Holkema, First English-language edition in 1972, Supports: an Alternative to Mass Housing, The Architectural Press, London and Praeger, New York.

HABRAKEN, J. 2010, John Habraken's Homepage, available at: http://www.habraken.org/

HABRAKEN, J., Boekholt, T., Thyssen, A. P., and Dinjens, P. J. M. 1976, Variations, the Systematic Design of Supports, MIT Press, Cambridge, USA

HONGLUN, H., SHOUQIAN, S., and YUNHE, P. 2007, Research on Virtual Human in Ergonomic Simulation, Computers \& Industrial Engineering, 53, pp. 350-356.

JIMENO, A. and PUERTA, A. 2007, State of the Art of the Virtual Reality Applied to Design and Manufacturing Processes, International Journal of Advanced Manufacturing Technologies, 33, pp. 866-874.

KENDALL, S. and TEICHER, J. 2000, Residential Open Building, E \& FN Spon, London and New York.

KOLAREVIC, B. and MALKAWI, A. M. (Eds.) 2005, Performative Architecture: Beyond Instrumentality, Spon Press, London.

LI, H., CHAN, N., HUANG, T., GUO, H. L., LU, W., and SKITMORE, M. 2009, Optimizing Construction Planning Schedules by Virtual Prototyping Enabled Resource Analysis, Automation in Construction, 18, pp. 912-918.

MAHONEY, D. P. 1997, Moving Beyond CAD, Computer Graphics World, 20(6), pp. 20-26.
MITCHELL, C. T. 1993, Redefining Designing from Form to Experience. New York: Van Nostrand Reinhold.

OXMAN, R. 2009, Performative Design: A Performancebased Model of Digital Architectural Design, Environment and Planning B: Planning and Design, 36, pp. 1026-1037.

PARK, H., MOON, H. C., and LEE, J. Y. 2009, Tangible Augmented Prototyping of Digital Handheld Products, Computers in Industry, 60(2), pp. 114-125.

PEKTAS, S. T. and ERKIP, F. 2006, Attitudes of Design Students toward Computer Usage in Design, International Journal of Technology and Design Education, 16(1), pp. 79-95.

PEKTAS, S. T. and PULTAR, M. 2006, Modelling Detailed Information Flows in Building Design with the Parameterbased Design Structure Matrix, Design Studies, 27, pp. 99122.

SANG, S .J., ZHAO, J. C., WU, H., CHEN, S. J., and AN, Q. 2010, Modelling and Simulation of a Spherical Mobile Robot, Computer Science and Information Systems, 7(1), pp. 51-62.

SANOFF, H. 1992, Integrating Programming, Evaluation and Participation in Design: A Theory Z Approach, Avebury, Aldershot,.

SHEN, Q. and GRAFE, M. 2007, To Support Multidisciplinary Communication in VR-based Virtual Prototyping of Mechatronic Systems, Advanced Engineering Informatics, 21, pp. 201-209.

TASLI, S. and SAGUN, A. 2002, Proposals for Creative Uses of Computer Graphics in Architectural Design, Digital Creativity, 13(3), pp. 189-192.

TIURI, U. AND HEDMAN, M. 1998, Developments Towards Open Building in Finland. Helsinki: Helsinki University of Technology.

WANG, G. G. 2002, Definition and Review of Virtual Prototyping, Journal of Computing and Information Science in Engineering (Transactions of the ASME), 2(33), pp. 232236. 
ZAMAN, Q. M. AND GANESAN, S. 1996, A Flexible Design Approach: Enhancing Public Housing Privatization Process in Hong Kong, In O. Ural, D. Altınbilek \& T. Birgönül, (Ed.s) XXIVth IAHS World Housing Congress: How to House a

Nation: The Challenge for the XXlst Century. Vol. 2, (pp.61525). Ankara, Turkey.

ZHU, Z. H., LAROSA, M., and MA, J. 2009, Fatigue Life Estimation of Helicopter Landing Probe Based on Dynamic Simulation, Journal of Aircraft, 46(5), pp. 1533-1543.

\section{Authors' Addresses:}

Şule Taşlı Pektaş (Corresponding Author)

Bilkent University

Faculty of Art, Design and Architecture

06800 Bilkent/Ankara

Turkey

tasli@bilkent.edu.tr

Bülent Özgüç

Bilkent University

Faculty of Art, Design and Architecture

06800 Bilkent/Ankara

Turkey

ozguc@bilkent.edu.tr

- 56 